\title{
What can we learn from facilitator and student perceptions of facilitation skills and roles in the first year of a problem-based learning curriculum? Michelle McLean*
}

Address: Department of Physiology Nelson R. Mandela School of MedicineUniversity of Natal, Durban South Africa, 4001

Email: Michelle McLean* - mcleanm@nu.ac.za

* Corresponding author

Published: 30 October 2003

BMC Medical Education 2003, 3:9

This article is available from: http://www.biomedcentral.com/1472-6920/3/9

(C) 2003 McLean; licensee BioMed Central Ltd. This is an Open Access article: verbatim copying and redistribution of this article are permitted in all media for any purpose, provided this notice is preserved along with the article's original URL.
Received: 29 August 2003

Accepted: 30 October 2003

\begin{abstract}
Background: The small group tutorial is a cornerstone of problem-based learning. By implication, the role of the facilitator is of pivotal importance. The present investigation canvassed perceptions of facilitators with differing levels of experience regarding their roles and duties in the tutorial.
\end{abstract}

Methods: In January 2002, one year after problem-based learning implementation at the Nelson R. Mandela School of Medicine, facilitators with the following experience were canvassed: trained and about to facilitate, facilitated once only and facilitated more than one six-week theme. Student comments regarding facilitator skills were obtained from a 200 I course survey.

Results: While facilitators generally agreed that the three-day training workshop provided sufficient insight into the facilitation process, they become more comfortable with increasing experience. Many facilitators experienced difficulty not providing content expertise. Again, this improved with increasing experience. Most facilitators saw students as colleagues. They agreed that they should be role models, but were less enthusiastic about being mentors. Students were critical of facilitators who were not up to date with curriculum implementation or who appeared disinterested. While facilitator responses suggest that there was considerable intrinsic motivation, this might in fact not be the case.

Conclusions: Even if they had facilitated on all six themes, facilitators could still be considered as novices. Faculty support is therefore critical for the first few years of problem-based learning, particularly for those who had facilitated once only. Since student and facilitator expectations in the small group tutorial may differ, roles and duties of facilitators must be explicit for both parties from the outset.

\section{Background}

The small group tutorial is one of the cornerstones of problem-based learning (PBL). By implication then, the role of the tutor/facilitator is of pivotal importance, as student learning would depend on the facilitator's understanding and appreciating of his/her responsibilities in the small group sessions [1,2]. Just as the finer details of the implementation of any PBL programme are unique to each institution, so will be the precise expectations of the facilitator. It is therefore necessary to make the expectations of facilitators explicit to staff and students from the outset. 
In an ideal situation, where classes are small, there may be sufficient experts to serve the dual role of tutor and facilitator, providing students with expertise while overseeing the group process [3]. In reality, however, medical faculties are generally not afforded such luxury in terms of human resources. In most instances, the tutor becomes a true facilitator, whose primary role is to ensure student learning and interaction during small group sessions. Prior to embracing facilitation, facilitators need to understand and accept the philosophy that underpins PBL. Each educator must therefore believe in the benefits of active, constructive learning and be able to relinquish teaching control, which historically, for the good teacher, meant explaining such that students understood. For many academics, PBL, as an educational philosophy, questions many of the epistemologies underlying their previous activities in a traditional didactic curriculum, which may be met with some resistance $[2,4]$. The transition from teacher to facilitator requires faculty to develop staff skills in PBL facilitation, through workshops and perhaps staff incentives [5-9].

Dolmans and co-workers, in a review article on the trends in tutor research, point out that although an extensive literature on facilitation exists, there is a need for more qualitative research into facilitator perceptions of their role in student learning in the small group setting [10]. The present study is such an evaluation - mainly staff with differing levels of facilitation experience but also some student perceptions of the role of the facilitator at the end of the first year of a PBL programme. Since the trend in curriculum reform in medical education is towards $\mathrm{PBL}$, the lessons learnt by those who have already begun the implementation process can provide valuable advice to those who are yet to embark on their new programme.

\section{Methods \\ The institutional setting}

In 1997, the Faculty Board of the Nelson R. Mandela School of Medicine (Faculty of Health Sciences, University of Natal, Durban, South Africa) resolved to replace the traditional discipline-based medical programme with a PBL curriculum. A Curriculum Development Task Force was established to construct the blueprints and matrixes for each 6-week theme (6 per year) for the 5-year programme. Year 1 was implemented in January 2001.

\section{Facilitator training}

In order to prepare staff for facilitation in the PBL programme, 3-day training workshops were undertaken at regular intervals from 2000 onwards. Some suitably qualified individuals outside the Faculty (e.g. general practitioners, staff at other universities, educationalists) were invited for training. Facilitators were thus drawn largely $( \pm 88 \%)$ from the academic staff (employed by the University, the regional provincial health department or on joint conditions of service) and other suitably qualified individuals (e.g. support staff with masters degrees in science).

The training programme was aimed at developing an epistemological basis for PBL, an understanding and appreciation of the small group tutorial process and specific facilitation skills. Role-playing (e.g. scribe, chair, facilitator) formed an integral component of the training. In the facilitator pack provided at the start of each 6-week theme, a two page summary of facilitation was included to remind facilitators of the essential principles of facilitation and to serve as a refresher for those who had undertaken the training several months earlier (Table 1).

Table I: Salient points in the summary provided to facilitators prior to a 6-week theme.

\begin{tabular}{ll}
\hline Point & Concept \\
\hline $\mathbf{2}$ & The interaction between facilitator and students must be at the metacognitive level \\
The relationship between the facilitator and students is one as would develop between colleagues, albeit some who are still \\
novices \\
It is imperative that you guide the students through all levels of the 8 steps, making sure each is dealt with before moving onto the \\
next \\
$\mathbf{5}$ \\
$\mathbf{6}$ & $\begin{array}{l}\text { Don't be judgemental about what the student has to say } \\
\text { Remember, you are not the font of all knowledge }\end{array}$ \\
$\mathbf{9}$ & Recognise the contributions students make \\
Never interrupt productive discussion \\
The groups exists over time and, as a consequence, may become inefficient or ineffective in its tasks due to disharmony amongst \\
group members \\
As a facilitator, you need to make sure not only that learning is happening within the group but that it is happening for all \\
members of the group \\
As a facilitator, you must keep the process going at a reasonable pace
\end{tabular}


Table 2: Reasons selected by facilitators for participating in the new PBL programme. Facilitators could select more than one option.

\begin{tabular}{ll}
\hline Reasons for facilitating & \% facilitators $(\mathbf{n}=\mathbf{3 3})$ \\
\hline I believe it is my responsibility to contribute to the new undergraduate programme & $\mathbf{8 7 . 9}$ \\
I believe in the philosophy of problem-based learning & $\mathbf{6 6 . 7}$ \\
It would contribute towards my teaching portfolio when applying for promotion \\
Financial reasons \\
My Head of Department/School asked me to facilitate \\
Facilitation is an opportunity to earn CPD points \\
Other (e.g. enjoy undergraduate teaching; interested in teaching and learning; to learn with students)
\end{tabular}

\section{Facilitator evaluation: the survey}

During 2001, 51 facilitators were utilised for the six themes (20 facilitators required per theme; 10 students per group) run during the first year of PBL. Of these, five had left the Faculty and five others were intimately involved in the development of the curriculum and were thus excluded from the survey. Prior to the start of the 2002 academic year, it was decided to survey facilitators with differing levels of facilitation experience during 2001. $61 \%$ of facilitators returned their questionnaires. Facilitators could this be classified into those who had

\section{Facilitated more than 1 theme $(n=17)$}

\section{Facilitated 1 theme only $(n=8)$}

3. Been trained and were about to facilitate for the first time in January $2002(n=8)$

In the survey, inquiries were made regarding motivation to facilitate, the role of training in their understanding of $\mathrm{PBL}$, their experiences of facilitation (e.g. difficulties and how they coped) and their perceived roles as a facilitator in student learning. Facilitators had to rate a statement on a 5-point Likert scale and were generally given an opportunity to explain their answers. For those who were still to facilitate, statements were worded such that their perceptions of what they should or would do were probed.

\section{Statistical analyses}

To check for significant differences within and between the three groups, one-way analysis of variance and a post hoc (LSD) test were undertaken. Where only two groups (facilitated once and facilitated more than once) were compared, a two-tailed student's $t$-test was applied once the values had been corrected for equality of variance using Levene's test. In both instances, a $P$ value $<0.05$ was considered significant.

\section{Student comments}

Although each facilitator was evaluated by his/her group following a 6-week theme, the comprehensive data are currently not available. Student comments reported were collected from a general evaluation of a number of different aspects of the new programme at the end of 2001. Students were asked to comment on the positive and negative aspects of the facilitator as a channel of communication between curriculum organisers and students. The comments received were, however, of a more general nature and provided insight into facilitators' abilities from the student perspective.

\section{Results}

\section{Motivation to facilitate}

It would appear that facilitation was generally being undertaken for the correct reasons (Table 2). Facilitators felt that it was their responsibility $(87.9 \%)$ and they believed in the PBL philosophy (66.7\%). There were, however, less intrinsic motivating factors. It was not surprising to find that almost $61 \%$ of facilitators (Table 2 ) were doing so for promotional purposes, considering that promotion now requires a teaching portfolio. Almost half indicated that payment was a consideration. In this regard, Faculty had decided that while the traditional programme was being phased out, facilitators and clinical skills tutors would be remunerated.

\section{Training}

Facilitator training had clearly been successful, with all three groups indicating that their understanding of PBL had increased as a result, and that the training had provided them with insight into the management of a small group (Table 3). This was confirmed after they had facilitated on at least one theme (Table 4). Once they had facilitated, the training made more sense, particularly for those who had facilitated more than once (Table 4) (94.1\% of those who had facilitated more than once vs. $62.5 \%$ of those who had facilitated once).

Despite the training, facilitators were, however, anxious or ambivalent prior to facilitating their first session (Table 3). Facilitating more than once allowed them to become better equipped with this new skill. Although there was agreement that their first experience had been positive, 
Table 3: Facilitators' perceptions of the impact of training on their knowledge of PBL and their sentiments regarding facilitation and their first small group experiences.

\begin{tabular}{|c|c|c|c|c|}
\hline & \multicolumn{3}{|c|}{ Level of experience } & \multirow[b]{2}{*}{$\begin{array}{l}\text { All facilitators } \\
\qquad(n=33)\end{array}$} \\
\hline & $\begin{array}{l}\text { No facilitation } \\
\quad(n=8)\end{array}$ & $\begin{array}{c}\text { Facilitated } \\
\text { once }(n=8)\end{array}$ & $\begin{array}{c}\text { Facilitated }>1 \\
\quad(n=17)\end{array}$ & \\
\hline \multicolumn{5}{|l|}{ Facilitator training } \\
\hline $\begin{array}{l}\text { PRIOR TO TRAINING, how would rate your knowledge/ } \\
\text { understanding of the PBL philosophy? I = none } 2=\text { scant } 3= \\
\text { reasonable/average } 4=\text { good } 5=\text { excellent }\end{array}$ & $2.5 \pm 0.38$ & $2.4 \pm 0.36$ & $3.0 \pm 0.24$ & $2.7 \pm 0.18$ \\
\hline $\begin{array}{l}\text { AFTER TRAINING, how would you rate your knowledge/ } \\
\text { understanding of the PBL philosophy? I = none } 2=\text { scant } 3= \\
\text { reasonable/average } 4=\text { good } 5=\text { excellent }\end{array}$ & $3.8 \pm 0.25$ & $3.9 \pm 0.30$ & $4.0 \pm 0.19$ & $3.9 \pm 0.13$ \\
\hline $\begin{array}{l}\text { Did the facilitator training provide you with sufficient insight into } \\
\text { how a facilitator should manage a small } P B L \text { group? I = strongly } \\
\text { disagree } 2 \text { = disagree } 3=\text { not sure } 4=\text { agree } 5 \text { = strongly } \\
\text { agree } \\
\text { Becoming experienced with facilitation }\end{array}$ & $3.9 \pm 0.30$ & $3.6 \pm 0.42$ & $3.8 \pm 0.24$ & $3.8 \pm 0.17$ \\
\hline $\begin{array}{l}\text { How did/do you feel before facilitating your first session? I = } \\
\text { annoyed } 2=\text { anxious } 3=\text { did not think about it } 4= \\
\text { confident } 5=\text { excited }\end{array}$ & $3.1 \pm 0.55$ & $2.9 \pm 0.40$ & $3.1 \pm 0.33$ & $3.0 \pm 0.31$ \\
\hline $\begin{array}{l}\text { Do you believe that in order to become more comfortable/ } \\
\text { equipped to facilitate, one must facilitate more than I theme? I = } \\
\text { strongly disagree } \mathbf{2}=\text { disagree } \mathbf{3}=\text { not sure } \mathbf{4}=\text { agree } \mathbf{5}= \\
\text { strongly agree }\end{array}$ & $4.6 \pm 0.18^{a}$ & $3.4 \pm 0.46^{b}$ & $4.4 \pm 0.24^{\mathrm{ac}}$ & $4.2 \pm 0.19$ \\
\hline \multicolumn{5}{|l|}{$\begin{array}{l}\text { Facilitation or teaching in the traditional programme? I = strongly } \\
\text { disagree } \mathbf{2}=\text { disagree } \mathbf{3}=\text { not sure } \mathbf{4}=\text { agree } \mathbf{5}=\text { strongly } \\
\text { agree }\end{array}$} \\
\hline $\begin{array}{l}\text { In terms of undergraduate learning, would you prefer to facilitate } \\
\text { (new curriculum) (rather than continue to teach students } \\
\text { didactically (i.e. lectures) as is undertaken in the traditional } \\
\text { curriculum)? }\end{array}$ & $3.9 \pm 0.30$ & $3.8 \pm 0.49$ & $3.3 \pm 0.34$ & $3.6 \pm 0.22$ \\
\hline $\begin{array}{l}\text { Have you ever consulted someone (MEDev or other) with regard } \\
\text { to problems that you may have experienced in your small group } \\
\text { sessions. }\end{array}$ & N/A & $3.3 \pm 0.49$ & $2.4 \pm 0.26$ & $\begin{array}{c}2.6 \pm 0.24 \\
25)\end{array}(n=$ \\
\hline
\end{tabular}

a,b,ac $P<0.05$

that they were enthusiastic about the process, and believed that it promoted student learning, those who had facilitated once only were less sure about some of these issues (Table 4).

Those who had facilitated once only did not encounter difficult students in their groups, while half of the more experienced group had had a disruptive or a non-participative student (Table 4). From facilitator comments, the situation was handled appropriately, by negotiation with the group or the individual, by directing questions to the quiet student or by reporting the incident to the Medical Education Development (MEDev) office.

\section{Facilitator perceptions of their roles}

There was general agreement (>80\% of facilitators) regarding facilitator roles in terms of student participation, not tutoring, assessing students and asking probing questions (Table 5). There was, however, some variability in the response of facilitators to less implicit roles (i.e. being a mentor or a role model, or viewing students as colleagues) (Table 5). Only the facilitated once group members were "not sure" about being role models. All three groups were, however, uncertain about their role as a mentor. Perhaps this arose as a result of different perceptions of the term "mentor", although an example was provided. Some facilitators believed that this role should be undertaken by a counsellor, while others were of the opinion that if a facilitator was to become an academic mentor, then he/she needed to be a subject expert, which was not possible in the current system. For others, a facilitator cannot have the dual role of mentor and assessor (albeit formative in this case) - "Facilitators and mentors should be separate to maintain objectivity in academic assessment". It is encouraging to find that facilitators generally saw students as colleagues, suggesting that they viewed themselves as learners in this process (Table 5).

Facilitators recognised that they were not supposed to provide content information, but some had found it diffi- 
Table 4: Facilitator experiences of their small groups tutorials: facilitating for the first time and dealing with student problems.

\begin{tabular}{|c|c|c|c|c|}
\hline & \multicolumn{2}{|c|}{ Level of experience } & \multirow[b]{2}{*}{$\begin{array}{l}\text { Student's t-test } \\
\quad \text { ( P value) }\end{array}$} & \multirow[b]{2}{*}{$\begin{array}{l}\text { All facilitators } \\
\quad(n=25)\end{array}$} \\
\hline & $\begin{array}{l}\text { Facilitated once } \\
\qquad(n=8)\end{array}$ & $\begin{array}{l}\text { Facilitated }>1 \\
\quad(n=17)\end{array}$ & & \\
\hline \multicolumn{5}{|l|}{ Facilitating the first theme } \\
\hline $\begin{array}{l}\text { How would you rate your first tutorial } / \text { facilitation session }(\text { i.e. } \\
\text { Case I)? } \mathbf{I}=\text { dreadful } \mathbf{2}=\text { satisfactory } \mathbf{3}=\text { not sure } \mathbf{4}=\text { good } \\
\mathbf{5}=\text { excellent }\end{array}$ & $3.8 \pm 0.37$ & $3.4 \pm 0.26$ & 0.387 & $3.5 \pm 0.21$ \\
\hline $\begin{array}{l}\text { After facilitating your first } 6 \text { week theme, how do you feel } \\
\text { generally about facilitation? I = hate it } \mathbf{2}=\text { doing it because I } \\
\text { have to } 3=\text { ambivalent } \mathbf{4}=\text { coping } 5=\text { enthusiastic }\end{array}$ & $4.5 \pm 0.27$ & $4.6 \pm 0.19$ & 0.795 & $4.6 \pm 0.15$ \\
\hline $\begin{array}{l}\text { After facilitating for one theme of } 6 \text { weeks, how did you feel } \\
\text { about the PBL process in terms of promoting learning in } \\
\text { Medicine? I = ineffective } 2 \text { = barely effective } \mathbf{3}= \\
\text { ambivalent } \mathbf{4} \text { = good } \mathbf{5}=\text { excellent }\end{array}$ & $4.3 \pm 0.31$ & $3.8 \pm 0.20$ & 0.195 & $3.9 \pm 0.17$ \\
\hline $\begin{array}{l}\text { Once you had facilitated I theme, did the facilitator training make } \\
\text { more sense in terms of understanding the role of the facilitator in } \\
\text { small group PBL sessions? I = strongly disagree } \mathbf{2}=\text { disagree } \\
\mathbf{3}=\text { not sure } \mathbf{4}=\text { agree } \mathbf{5}=\text { strongly agree }\end{array}$ & $3.6 \pm 0.46$ & $4.1 \pm 0.12$ & 0.331 & $4.0 \pm 0.17$ \\
\hline $\begin{array}{l}\text { After facilitating I theme, did your opinion of } \mathrm{PBL} \text { being beneficial } \\
\text { in terms of student learning change? I = strongly disagree } \mathbf{2}= \\
\text { disagree } \mathbf{3}=\text { not sure } \mathbf{4}=\text { agree } \mathbf{5}=\text { strongly agree }\end{array}$ & $3.0 \pm 0.42$ & $3.4 \pm 0.26$ & 0.462 & $3.3 \pm 0.22$ \\
\hline \multicolumn{5}{|l|}{$\begin{array}{l}\text { Facilitating with problem students } \\
I=\text { strongly disagree } 2=\text { disagree } 3=\text { not sure } 4=\text { agree } \\
5=\text { strongly agree }\end{array}$} \\
\hline $\begin{array}{l}\text { Did you ever find that a tutorial group was difficult to control in } \\
\text { terms of your understanding of how a small group should } \\
\text { function? }\end{array}$ & $1.8 \pm 0.25$ & $1.9 \pm 0.17$ & 0.663 & $1.8 \pm 0.14$ \\
\hline Did any student in one of your groups disrupt the group process? & $1.5 \pm 0.27$ & $3.1 \pm 0.29$ & $0.00 I^{*}$ & $2.6 \pm 0.26$ \\
\hline $\begin{array}{l}\text { Did any student in one of your groups not participate in the } \\
\text { discussions? }\end{array}$ & $2.0 \pm 0.33$ & $3.1 \pm 0.33$ & $0.033^{*}$ & $2.7 \pm 0.26$ \\
\hline
\end{tabular}

*indicates a statistical difference $(P<0.05)$

Table 5: Facilitators' responses with respect to their perceptions of the roles of a facilitator.

\begin{tabular}{|c|c|c|c|c|}
\hline \multirow[b]{2}{*}{$\begin{array}{l}\text { Roles of a facilitator } \\
I=\text { strongly disagree } 2=\text { disagree } 3=\text { not sure } 4=\text { agree } 5= \\
\text { strongly agree }\end{array}$} & \multicolumn{3}{|c|}{ Level of experience } & \multirow[b]{2}{*}{$\begin{array}{l}\text { All facilitators } \\
\quad(n=33)\end{array}$} \\
\hline & $\begin{array}{l}\text { No facilita- } \\
\text { tion }(n=8)\end{array}$ & $\begin{array}{l}\text { Facilitated } \\
\text { once }(n=8)\end{array}$ & $\begin{array}{l}\text { Facilitated }>1 \\
\quad(n=17)\end{array}$ & \\
\hline Ensuring the small group process runs smoothly & $4.8 \pm 0.16$ & $4.4 \pm 0.18$ & $4.0 \pm 0.30$ & $4.3 \pm 0.17$ \\
\hline Ensuring that all students participate equally in the group & $4.3 \pm 0.31$ & $4.4 \pm 0.18$ & $4.1 \pm 0.27$ & $4.2 \pm 0.16$ \\
\hline Assessing individual students in the group & $4.5 \pm 0.19$ & $4.3 \pm 0.16$ & $4.1 \pm 0.23$ & $4.2 \pm 0.14$ \\
\hline $\begin{array}{l}\text { Communicating messages from curriculum organisers to students at } \\
\text { each session }\end{array}$ & $4.1 \pm 0.30$ & $3.9 \pm 0.35$ & $3.5 \pm 0.37$ & $3.7 \pm 0.22$ \\
\hline $\begin{array}{l}\text { Through probing questions, ensuring that the group achieves their } \\
\text { learning goals }\end{array}$ & $4.5 \pm 0.19$ & $3.9 \pm 0.23$ & $3.9 \pm 0.26$ & $4.1 \pm 0.16$ \\
\hline Not tutoring, i.e. not providing expert knowledge related to the case & $4.4 \pm 0.26$ & $3.9 \pm 0.30$ & $4.2 \pm 0.25$ & $4.2 \pm 0.16$ \\
\hline $\begin{array}{l}\text { Do you think that a facilitator should treat learners in small group } \\
\text { sessions as colleagues despite them being neophytes? }\end{array}$ & $4.0 \pm 0.42$ & $3.1 \pm 0.48$ & $3.7 \pm 0.28$ & $3.6 \pm 0.21$ \\
\hline $\begin{array}{l}\text { Do you think that a facilitator should become a mentor (e.g. in whom } \\
\text { students can confide) for learners in his/her group? }\end{array}$ & $3.6 \pm 0.32$ & $3.3 \pm 0.45$ & $3.4 \pm 0.24$ & $3.4 \pm 0.18$ \\
\hline $\begin{array}{l}\text { Do you think that a facilitator should serve as a role model (i.e. } \\
\text { professional behaviour; ethical, etc.) for learners in his/her group? }\end{array}$ & $4.3 \pm 0.16^{\mathrm{ab}}$ & $3.4 \pm 0.46^{a}$ & $4.3 \pm 0.2 I^{b}$ & $4.1 \pm 0.17$ \\
\hline $\begin{array}{l}\text { Did you/will you find it difficult not to share your expertise with } \\
\text { students during sessions? }\end{array}$ & $3.3 \pm 0.45$ & $3.4 \pm 0.53$ & $2.4 \pm 0.31$ & $2.9 \pm 0.24$ \\
\hline
\end{tabular}

$\mathrm{a}, \mathrm{b}, \mathrm{ab} P=0.025$ 
Table 6: Facilitator perceptions of their ability to undertake certain tasks during the small group tutorials $(I=$ ineffective $2=$ weak $3=$ satisfactory $4=$ good $5=$ excellent; $P=0.05$ ).

\begin{tabular}{|c|c|c|c|c|}
\hline \multirow[b]{2}{*}{ Facilitator ability to } & \multicolumn{3}{|c|}{ Level of experience } & \multirow[b]{2}{*}{$\begin{array}{l}\text { All facilitators } \\
\quad(n=33)\end{array}$} \\
\hline & $\begin{array}{l}\text { No facilitation } \\
\quad(n=8)\end{array}$ & $\begin{array}{l}\text { Facilitated once } \\
\quad(n=8)\end{array}$ & $\begin{array}{l}\text { Facilitated }>1 \\
\quad(n=17)\end{array}$ & \\
\hline $\begin{array}{l}\text { Ask probing questions to get students to think about issues } \\
\text { relating to the case }\end{array}$ & $4.4 \pm 0.26$ & $3.8 \pm 0.31$ & $4.1 \pm 0.13$ & $4.1 \pm 0.12$ \\
\hline Encourage students to clarify their ideas & $4.3 \pm 0.16^{\mathrm{a}}$ & $3.8 \pm 0.16^{b}$ & $4.0 \pm 0.2^{\mathrm{ab}}$ & $4.0 \pm 0.09$ \\
\hline Encourage students to examine new ideas & $4.4 \pm 0.18^{a}$ & $3.6 \pm 0.26$ & $3.9 \pm 0.12^{c}$ & $3.9 \pm 0.11$ \\
\hline Point out inconsistencies in their explanations & $3.5 \pm 0.50$ & $3.5 \pm 0.33$ & $3.7 \pm 0.19$ & $3.6 \pm 0.17$ \\
\hline Get students to effectively brainstorm hypotheses & $4.6 \pm 0.18^{a}$ & $3.9 \pm 0.13^{b}$ & $4.0 \pm 0.19 b c$ & $4.1 \pm 0.12$ \\
\hline $\begin{array}{l}\text { Encourage students to utilise their prior experience to the } \\
\text { benefit of the group }\end{array}$ & $4.6 \pm 0.18^{a}$ & $3.3 \pm 0.16 b$ & $4.2 \pm 0.14 \mathrm{ac}$ & $4.1 \pm 0.13$ \\
\hline Encourage all group members to contribute & $4.6 \pm 0.18$ & $4.0 \pm 0.33$ & $4.1 \pm 0.20$ & $4.2 \pm 0.14$ \\
\hline Support each member of the group & $4.5 \pm 0.19$ & $3.9 \pm 0.35$ & $3.9 \pm 0.23$ & $4.1 \pm 0.16$ \\
\hline Ensure that everyone has a chance to contribute & $4.8 \pm 0.16^{a}$ & $3.9 \pm 0.30^{b}$ & $4.2 \pm 0.15^{b c}$ & $4.2 \pm 0.12$ \\
\hline $\begin{array}{l}\text { Encourage students to extend themselves beyond the learning } \\
\text { objectives (i.e. instill in them that knowledge is not finite or can } \\
\text { change) }\end{array}$ & $4.6 \pm 0.18^{a}$ & $3.8 \pm 0.25 b$ & $4.0 \pm 0.2 I^{\mathrm{ab}}$ & $4.1 \pm 0.14$ \\
\hline Test for agreement between group members & $3.6 \pm 0.32$ & $3.5 \pm 0.27$ & $3.9 \pm 0.17$ & $3.7 \pm 0.13$ \\
\hline Encourage students to read widely & $4.6 \pm 0.18^{a}$ & $3.6 \pm 0.26 b$ & $3.8 \pm 0.16^{\mathrm{bc}}$ & $3.9 \pm 0.13$ \\
\hline Summarise the progress of the group & $4.0 \pm 0.38$ & $3.6 \pm 0.26$ & $3.8 \pm 0.18$ & $3.8 \pm 0.14$ \\
\hline
\end{tabular}

cult not to tutor students, particularly those who had facilitated once only (Table 5). It appeared to become easier to facilitate and not tutor with increasing facilitation experience (Table 5).

\section{Self-evaluation}

When asked about their ability to perform various expected functions in the small group tutorial, more than three-quarters of the experienced facilitators rated their ability in many domains as good/excellent (Table 6). Those who were about to facilitate were extremely confident in this regard, while those who had facilitated once only were somewhat sceptical, with the average for this group below the mean for all facilitators in all instances (Table 6). Understandably, the 'experienced' facilitators were a little more realistic than either of the other two groups.

For many of the duties, statistical differences were recorded, generally between those who had not facilitated and those who had (Table 6). Testing for agreement between group members, pointing out inconsistencies and summarising the group process were areas in which all three groups rated their abilities lower than other tasks. Facilitators who had facilitated once only rated their ability to activate prior knowledge as satisfactory, whereas those who had facilitated more than once rated their ability as good (Table 6). The results suggest that facilitator perceptions of their abilities improved with experience.

\section{PBL or the traditional curriculum?}

Perhaps the most important questionnaire item relates to whether facilitators would prefer to teach in the traditional curriculum or facilitate in PBL (Table 3). $57.6 \%$ of all facilitators would rather facilitate than teach. Surprisingly, just over one-third of the most experienced group would rather teach than facilitate, explaining the "not sure" response to this item in Table 3 . There were clearly mixed sentiments regarding PBL as an educational philosophy replacing the traditional programme.

"Teaching didactically is spoon-feeding" (not in favour of the traditional programme).

"I prefer to lecture. I am 100\% sure of what is expected of me. Students are $100 \%$ sure of what is expected of them" (in favour of the traditional programme).

"PBL promotes continued gain of knowledge and assists weaker students" (in favour of PBL).

"I would prefer to do both. Lectures are a way of giving basic knowledge. Groups are for further learning" (in favour of a hybrid system).

\section{Student comments}

Table 7 summarises comments of students offered in a survey conducted at the end of 2001. While some facilitators were praised for their personal traits and facilitation 
Table 7: Positive and negative student comments pertaining to facilitators.

\section{Facilitation skills}

- Helped us get used to the meetings and facilitate group interaction.

- Some direct the sessions well. They give positive input and encourage group members.

- Only once I had a facilitator who always asked us problems we were faced with and would give us feedback about the subject matter. This reinforced our feeling towards the facilitator as being one of us.

- One gets to understand the work that one might have misunderstood.

- Very helpful guides. I have been lucky. All my facilitators were great and stimulated my interest in learning or participating and they encouraged me though sometimes they made me feel like I didn't do my work for Friday, when I came confident.

Personal traits

- Some facilitators genuinely care and always came back with a response.

- Very informative and friendly.

\section{Negative comments}

\section{Poorly informed with regard to the curriculum}

- They don't understand the problems and formats of timetables and exams. They feel out of place relaying information.

- Some facilitators never report on their facilitator meetings. If they don't know, we don't know.

- Some facilitators misinterpret the information and misinform students.

- Some were too busy to find out anything and others speculated about answers to our questions, e.g. OSCEs.

- Very little feedback - "We are looking into it" is a common response.

- Some facilitator failed to respond to questions related to the notices.

- Facilitators themselves don't often seem to know what is happening. They don't seem to have the BIG PICTURE regarding Curriculum $200 \mathrm{I}$ and its workings.

- They sometimes don't know much about the process of MEDev.

- Facilitators seem to know little about IMPORTANT issues such as formative and summative assessment.

Not enthusiastic

- Some facilitators do not show enthusiasm for the new curriculum/PBL process.

- Sometimes facilitators cannot help us as most of them are not familiar with the present programme.

- Facilitators cannot always do stuff to help.

- Some facilitators have no interest. They sit there, get paid, answer their phones and leave.

Poor facilitator role

- Some notices are read at the end of the meeting when nobody has any interest in them.

- They do not seem to know their role in the PBL process. They are either too subdued or dominated the sessions.

- Some facilitators interfere with the group process.

- There is a problem if the facilitator cannot communicate, if the facilitator is not interested or cannot identify with the group's problem.

- Some make you panic from the first day.

- Some are not well informed on how they should facilitate and so end up telling us everything or nothing.

- Sometimes they did not take us seriously and therefore tended not to give us an opportunity to express ourselves.

- Some of them do not read the notices.

Personal issues

- Some individuals are not as dedicated/approachable as is necessary to facilitate easy interaction between students and staff.

- Cannot address anything personal.

- Sometimes you find the facilitator favours other students.

Other comments

- Some facilitators know less than us.

- The role of the facilitator is very important and it seems to be underestimated by the planners. Some facilitators are a real waste of time whilst others are a key part of the group. How can there be such a variety of attitudes of facilitators when they supposedly all know what to do? Some of them are just unpleasant, boring never enthusiastic, never on time! How can these people be picked to do such an important job? Yes, they are not there to teach but at least be happy and say something or contribute a little. Students get terribly depressed when they hear that $M$ has facilitator $X$ and $N$ has facilitator $Y$. This should not be the case. Facilitator training should be looked at because something (with our facilitators) went WRONG! Some facilitators are very informed whilst others are just as lost as we are. How can the blind lead the blind? MAYBE at the start of the year, the facilitator's role should have been explained to the students. 
skills (which have suggestions of tutoring in some cases!), others were criticised for poor facilitation skills, lack of enthusiasm and being uninformed about the new curriculum.

\section{Discussion}

There were a wide range of responses regarding facilitator skills and roles, both from the student and the facilitator perspective. The level of experience impacted on facilitator perceptions of their ability to undertake certain facilitation duties and tasks. On self-evaluation, most facilitators believed that they could adequately manage the group process, although some found it difficult not to share their expertise. Students were, however, more severe in their criticism of facilitator abilities, where there were clearly differences in perceived level of facilitator skill and commitment. These results suggest a need for more explicit instructions to both staff and students regarding expectations of facilitators in the programme.

\section{Facilitator motivation}

While some negative student comments pertained to facilitator performance in the group process (e.g. interfering with the group process), others related to facilitators not being in touch with programme details (e.g. timetables, assessment procedures). Since 2001 was the first year of PBL implementation, with many aspects evolving, it is understandable that some facilitators were not always aware of the latest developments. Facilitator meetings with curriculum organisers arranged prior to the start of the theme and at least once during the 6 weeks, served to inform facilitators of the scope of the learning objectives and problems to be addressed. The question arises whether this intervention, as well as other reports presented to Faculty Board, provided sufficient information regarding curriculum implementation. Of interest, and an issue for debate, would be the consideration of the dual responsibility of facilitators and curriculum developers in this regard (i.e. of becoming informed and of being informed). Since facilitators are being paid during the early stages of PBL implementation, while the traditional curriculum is being phased out, should they then not make every effort to keep abreast of Curriculum 2001 developments? Only 50\% of facilitators $(<30 \%$ of the more experienced) had contacted MEDev with a query, suggesting a degree of apathy. Almost half of the facilitators were prompted to facilitate for financial reasons, which may question their recorded intrinsic motivation (i.e. felt it was their responsibility, believed in the PBL philosophy) (Table 2).

\section{Content expert vs. non-expert facilitator}

An important and not unexpected outcome of this survey was the issue of tutoring (i.e. providing content expertise). There is considerable literature on the content expert vs. the non-expert in $\mathrm{PBL}$, the results of which are contradictory in terms of the impact on student learning [10-12]. While facilitators in the present survey understood that they were not to share their content expertise, many were unable to restrain themselves. Tutors new to PBL have been reported elsewhere to experience the same difficulty, which carries with it the danger of directing the tutorial process [13-16]. Silver and Wilkerson, following their study on tutors' self-rating of their expertise and performance, believe that dominant tutors may impede students' ability to prioritise learning goals, ask and answer critical questions and synthesize their learning [17]. Content experts also found it more difficult to maintain the facilitator role, but that if they did, they were more satisfied with PBL as an educational process [15]. Perhaps the marginal preference of facilitators in the present study to facilitate in the new programme vs. lecture in the old one indicates an underlying uneasiness with their changing role in student learning. Despite most facilitators enjoying their sessions and believing that PBL promoted student learning, only $57.6 \%$ would prefer to facilitate (vs. teach). This may, in part, reflect Oliffe's comments that PBL facilitation provides little nourishment for the traditional teaching ego [2]. Maudsley has summarised the changing role of the facilitator/tutor most eloquently: "The tutor's challenge is to forego the tightrope of effectiveness by balancing intervention in the group process between an informal, empathetic style and sparing use of personal content expertise" (p. 660)[11]. It might then take more than a 3-day training workshop to develop an appropriate ethos in staff in terms of embracing the new pedagogy. While almost $88 \%$ of facilitators felt that it their responsibility to participate, only $67 \%$ did so because they believed in PBL. This figure is only slightly higher than for those who were facilitating for promotional purposes. Again, such a response might indicate that some facilitators were not sufficiently intrinsically motivated by curriculum change, the reasons for which may be numerous (e.g. perhaps not seen as a faculty priority; work overload; not sufficiently informed). Clearly, it is in a faculty's interest that staff members willingly accept curriculum reform and volunteer as facilitators, theme co-ordinators, clinical skills tutors, etc. without extrinsic motivating factors such as remuneration. The difficulty arises, however, in the face of a human resource shortage, with many having clinical duties, postgraduate students and teaching commitments in the traditional programme. The phasing out of one programme and the implementation of another, particularly if the latter is of shorter duration, places considerable demands on staff. Incentives such as merit notches and promotion might therefore be necessary to encourage participation during this difficult interim period. Ideally, these measures should be in place prior to programme implementation. Faculty might consider suspending student registration for a year, to release some staff to assist with 
planning and to develop the human resource capacity to undertake the first year of implementation.

\section{Novice facilitators: improving skills}

Since the present survey was undertaken after only one year of the new programme, all facilitators, even if they had facilitated all six themes, could still be considered as novices in terms of their skills and role in PBL tutorials. Perhaps for some, the new programme challenged their epistemological beliefs and conceptions of teaching and learning [18], which they might (or might not have) espoused for as long as they had been teaching students. A new programme will undoubtedly place new demands on staff, impacting on their comfort zone, generating uncertainty, unease $[10,19]$ and even resistance $[2,4,20]$. Facilitator support, particularly in the early stages of PBL implementation, therefore becomes critical. Whilst Faculty organised meetings with facilitators during the themes, attendance was not always guaranteed due to other commitments (e.g. clinical duties, teaching in the old programme). Feedback to individual facilitators following student evaluation [1] as well as peer evaluation (e.g. presiding over a small group session) would be two ways in which facilitators could become confident in their facilitation skills. This feedback should be as early as possible, preferably before the next facilitation. This is, however, not always possible as it places additional demands on already busy curriculum organisers.

Facilitation expertise can be expanded by becoming a member of an informal, but preferably, a formal facilitator group. The former was created at the Nelson R. Mandela School of Medicine by facilitators who evidently found a need to share experiences, meeting over lunchtime to discuss areas of interest, problems, etc. An electronic interest group was also started for those who experience difficulty attending such meetings. For novice facilitators, peer assistance with issues such as dealing with quiet or disruptive students might offer more constructive support than can be provided by busy curriculum organisers. The latter should, however, not be used as an excuse by Faculty for not providing support. Since the small group tutorial and, by implication, facilitation, is a cornerstone of PBL, appropriate support structures (e.g. a staff development office) should be in place at implementation.

Strategies staff developers might consider to support facilitators could include co-facilitation, in which a novice facilitator attends sessions of a more experienced facilitator deemed to be "excellent" (by whom, as there is frequently a mismatch between perceptions of faculty and students?). Alternatively, videotaped sessions could provide a more permanent record of the process within groups [5], to be used during training sessions to highlight types of intervention and handling of difficulties.

\section{Non-cognitive roles of facilitators: neglected considerations?}

A much neglected but integral aspect of facilitation involves the non-cognitive roles of facilitators: as colleagues, role models and mentors. In a recent review article, Dolmans and colleagues summarise what they believe to be the three major trends in tutor research (content expertise; process variables; tutor characteristics in relation to differential content variables) and have suggested that in order to provide better insight into interpreting facilitator behaviour, future research should comprise qualitative studies regarding facilitators' conceptions of their role in student learning [10]. In one of the few publications which considers the non-cognitive role of facilitators in the group process, Schmidt and Moust, despite advocating content expertise as a requirement, propose a model incorporating social congruence (a willingness of a tutor to develop an informal relationship with students and display a personal interest and a caring attitude) as an important variable affecting not only the manner in which the facilitator explains things to students, but also on group functioning [3].

The present study attempted to gauge facilitator perceptions of their relationship with students, apart from their role as a process expert. It is encouraging that $\pm 64 \%$ of all facilitators ( $\pm 71 \%$ of experienced facilitators) recognised that they should treat students as colleagues, suggesting that many facilitators may have made the transition from teacher/lecturer to facilitator/educator, have embraced the PBL philosophy and are able to acknowledge that they too, as non-content experts, are learners with the students.

Facilitators generally agreed that they should serve as role models for students, which is congruent with the literature regarding the importance of role models for developing professional and ethical behaviour in students [21]. Facilitators were, however, less certain about their role as a mentor (only about 55\% agreement). The variable perceptions of a mentor may have contributed to this uncertainty [22], although an example was provided in the survey (e.g. someone in whom students can confide). Since mentoring involves an active participation on the part of the facilitator (e.g. being available for consultation outside of the group; dealing with personal student issues). counselling skills might be a useful inclusion in facilitator training. In all probability, however, for educators still grappling to come to terms with the PBL philosophy, and understanding their new role in student learning and development, mentoring might be an overwhelming concept. 


\section{Conclusions}

In order to effect student learning in the small group PBL session, the facilitator must be informed about and be acutely aware of his/her role and specific duties as identified by the particular institution. Through training workshops, where appropriate role-playing is a key element, trainee facilitators should develop a clear understanding of what they should and should not do in the tutorial. They must also be fully aware of their actions (e.g. divulging content) on student learning and behaviour. Content experts who have difficulty in switching from a conveyer of information to a facilitator of student learning should be informed as to how to redirect their expertise more effectively in terms of the PBL pedagogy. To this end, they should be encouraged to help students monitor their own learning, ask probing questions and assist students to see connections [10]. In the same vein, students should also be fully informed about the skills required of a facilitator, as there is often a mismatch between faculty and student expectations.

An effective facilitator should be committed to the pedagogic philosophy underpinning learning in PBL and should realise how his/her behaviour (e.g. being punctual, tolerant, motivated, fair, etc.) might impact on the attitudes students develop towards their colleagues, staff and ultimately their patients (i.e. role modelling) [17]. One must bear in mind that facilitator performance might be influenced by several contextual factors [9,16,23]: student prior knowledge, familiarity with the PBL tutorial process, problem design [16], department affiliation, group composition [9], cultural and gender differences [24] and group productivity [10]. Despite the small sample size of the present study, the results suggest that the facilitator group that had facilitated once only requires special attention in order to provide encouragement, bolster confidence and perhaps sustain the initial enthusiasm, which appeared to wane somewhat after their initial experiences. Faculty development of facilitators is therefore necessary and should be sustained, particularly during the early years of PBL implementation, when all facilitators are novices.

\section{List of abbreviations}

MEDev, Medical Education Development

PBL, problem-based learning

\section{Competing interests}

None declared.

\section{References}

I. Dolmans DHLM, Wolfhagen IHAP, Schmidt HG and van der Vleuten CPM: A rating scale for tutor evaluation in a problem-based learning curriculum: validity and reliability. Med Educ 1994, 28:550-558.
2. Oliffe J: Facilitation in PBL - espoused theory versus theory in use. AEJNE 2000, 5:

3. Schmidt HG and Moust JHC: What makes a tutor effective? A structural-equations modelling approach to learning in problem-based learning curricula. Acad Med 1995, 70:708-7|4.

4. Thompson DG and Williams RG: Barriers to the acceptance of problem-based learning in medical schools. Stud Higher Educ 1985, 10:199-204.

5. Tipping J, Freeman RF and Rachis AR: Using faculty and student perceptions of group dynamics to develop recommendations for PBL training. Acad Med 1995, 70:1050-1052.

6. Evans PA and Taylor DCM: Staff development of tutor skills for problem-based learning. Med Educ 1996, 30:365-366.

7. De Grave WS, Dolmans HJM and van der Vleuten CPM: Tutor intervention profile: reliability and validity. Med Educ 1998, 32:262-268

8. Olmesdahl PJ and Manning DM: Impact of training on PBL facilitators. Med Educ 1999, 33:753-755.

9. Dolmans DHJM, Wolfhagen IHAP, Hoogenboom RJI and van der Vleuten CPM: Is tutor performance dependent on the tutorial group's productivity? Towards further resolving of inconsistencies in tutor performance:. Teach \& Learn Med 1999, II:|86-19|.

10. Dolmans DHJM, Gijselaers WJ, Moust JHC, De Grave WS, Wolfhagen IHAP and van der Vleuten CPM: Trends in research on the tutor in problem-based learning: conclusions and implications for educational practice and research. Med Teach 2002, 24:173-180.

II. Maudsley G: Roles and responsibilities of the problem based learning tutor in the undergraduate medical curriculum. $B M]$ 1999, 7:320-323.

12. Hay PJ and Katsikitis M: The 'expert' in problem-based and casebased learning: necessary of not? Med Educ 200I, 35:22-26.

13. Thomas RE: Teaching medicine with cases: Student and teacher opinion. Med Educ 1992, 26:200-207.

14. Des Marchais JE, Bureau MA, Dumais B and Pigeon G: From traditional to problem-based learning: a case report of complete curriculum reform. Med Educ 1992, 26:190-199.

15. Kaufman DM and Holmes DB: The relationship of tutors' content expertise to interventions and perceptions in a PBL medical curriculum. Med Educ 1998, 32:255-261.

16. Neville AJ: The tutor in small-group problem-based learning: Teacher? Facilitator? Evaluator? Med Teach 1999, 21:393-40।.

17. Silver $M$ and Wilkerson L: Effects on tutors with subject expertise on the problem-based tutorial process. Acad Med 1991, 66:298-300.

18. Ramsden P: Learning to Teach in Higher Education. London, Kogan Press; 1992.

19. McLean M: Rewarding teaching excellence. Can we measure teaching 'excellence'? Who should be the judge? Med Teach 200I, 23:6-II.

20. Doring A, Bramwell-Vial A and Bingham B: Staff comfort/discomfort with problem-based learning. A preliminary study. Nurse Edu Today 1995, 15:263-266.

21. Skeff KM and Mutha S: Role models - guiding the future of medicine. New Eng J Med 1998, 339:2015-7.

22. Bulstrode $C$ and Hunt V: What is mentoring? The Lancet 2000, 356: 1788.

23. Gijselaers WH: Effects of contextual factors on tutor behaviour. Teach \& Learn Med 1997, 9:1 16-I24.

24. Das M, Mpofu DJS, Hasan MY and Stewart TS: Student perceptions of tutor skills in problem-based learning tutorials. 2002, 36:272-278.

\section{Pre-publication history}

The pre-publication history for this paper can be accessed here:

http://www.biomedcentral.com/1472-6920/3/9/prepub 